\title{
Outbreak of Salmonella enteritidis phage type 1B associated with frozen pre-cooked chicken cubes, Finland 2012
}

\author{
S. HUUSKO ${ }^{1 *}$, A. PIHLAJASAARI ${ }^{2}$, S. SALMENLINNA ${ }^{1}$, J. SÕGEL $^{3}$, \\ I. DONTŠENKO ${ }^{4}$, E. DE PINNA ${ }^{5}$, H. LUNDSTRÖM ${ }^{2}$, S. TOIKKANEN ${ }^{1}$ AND \\ R. RIMHANEN-FINNE ${ }^{1}$ \\ ${ }^{1}$ Department of Infectious Diseases, National Institute for Health and Welfare (THL), Helsinki, Finland \\ ${ }^{2}$ Finnish Food Safety Authority Evira, Helsinki, Finland \\ ${ }^{3}$ Veterinary and Food Board, Tallinn, Estonia \\ ${ }^{4}$ Health Board, Tallinn, Estonia \\ ${ }^{5}$ Public Health England, London, UK
}

Received 20 December 2016; Final revision 1 June 2017; Accepted 2 June 2017;

first published online 3 August 2017

\section{SUMMARY}

In August to October 2012, a nationwide outbreak of Salmonella enteritidis phase type (PT) 1B with 53 cases occurred in Finland. Hypothesis generating interviews pointed toward ready-to-eat chicken salad from a Finnish company and at the same time Estonian authorities informed of a S. enteritidis PT 1B outbreak linked to chicken wrap prepared at an Estonian restaurant. We found that chicken salad was associated with the infection (odds ratio (OR) 16.1, 95\% confidence interval (CI) $1 \cdot 7-148 \cdot 7$ for consumption and OR $17 \cdot 5.95 \%$ CI $4 \cdot 0-76 \cdot 0$ for purchase). The frozen pre-cooked chicken cubes used in Finnish salad and in Estonian wraps were traced back to a production plant in China. Great Britain made two Rapid Alert Systems for Food and Feed notifications on chicken cubes imported to the UK from the same Chinese production plant. Microbiological investigation confirmed that the patient isolates in Estonia and in Finland were indistinguishable from the strains isolated from chicken cubes in Estonia and in the UK. We recommend that despite certificates for tested Salmonella, food items should be analyzed when Salmonella contamination in outbreak investigations is suspected. In outbreak investigations, electronically implemented case-case study saves time, effort, and money compared with casecontrol study.

Key words: Case-case study, case-control study, frozen pre-cooked chicken cubes, outbreaks, Salmonella.

\section{INTRODUCTION}

Salmonella enteritidis is one of the serotypes most frequently associated with human illness [1]. In 2015, 1656 salmonellosis cases were reported in Finland

\footnotetext{
* Author for correspondence: S. Huusko, National Institute for Health and Welfare (THL), Infectious Disease Control Unit, P.O. Box 30, 00271 Helsinki, Finland.

(Email: sari.huusko@thl.fi)
}

(annual incidence of 30/1 00000 population) and 1583 Salmonella strain samples from these cases were sent to the National Institute for Health and Welfare (THL). Of these, $1238(78 \%)$ were infections of foreign and $311(20 \%)$ of domestic origin. S. enteritidis was the second most frequent serotype of domestic origin (59 cases, 19\%) after Salmonella typhimurium [2].

$S$. enteritidis infections in humans are often associated with the consumption of contaminated eggs and poultry meat [1]. Salmonella, however, rarely 
appears among production animals in Finland [3]. In connection with joining the European Union (EU) in 1995, Finland established a national Salmonella control program aimed at keeping the prevalence of Salmonella in production animals and foodstuffs originating from these below the level of $1 \%$ annually. For egg and meat production poultry, this target has mostly been achieved.

In Finland, 0-3 Salmonella outbreaks have been reported yearly in the period 2010-2015, the most common vehicles being vegetables and meat products [2-6]. In addition to contaminated raw material, infected staff members have been the main route of contamination in the Finnish Salmonella outbreaks [7]. In Finland, a majority of the reported Salmonella infections occur after travelling abroad [2].

In September 2012, the Bacteriology Unit of THL reported an increased number of domestic $S$. enteritidis phase type (SE PT) 1B cases from different parts of the country. Of 20 strains genotyped, 13 were identical and showed a rare genotype SENT 117. The samples had been taken between 8 June and 10 September 2012. At the same time, SE PT 1B outbreak occurred in Estonia. Epidemiological, traceback, and laboratory investigations were initiated to determine the magnitude and source of the outbreak in order to prevent further cases and similar outbreaks in the future.

\section{MATERIALS AND METHODS}

\section{Microbiological investigation}

Clinical microbiology laboratories in Finland notify all Salmonella cases to the national infectious disease register and send most isolates for typing to THL. Isolates were serotyped by slide agglutination method [8] and tested for antimicrobial sensitivity by means of disk diffusion method for ampicillin, chloramphenicol, trimetoprim, ciprofloxacin, gentamycin, nalidixic acid, cefoxitin, mesillinam, and imipenem according to the guidelines of the European Committee on Antimicrobial Susceptibility Testing [9]. For streptomycin, sulphonamid, and tetracycline, the sensitivity testing was also performed according to EUCAST method, but breakpoints were interpreted according to the guidelines from the Clinical and Laboratory Standards Institute [10]. Salmonella enterica serotype enteritidis isolates were further typed by phages [11] and genotyped by pulsed-field gel electrophoresis (PFGE) according to Pulse-Net protocol [12]. Salmonella isolates from four Estonian patients and from a chicken wrap from an Estonian restaurant were typed by the same methods as the Finnish isolates. Based on the traceback investigation, samples of frozen pre-cooked chicken cubes were collected from a wholesale storage and a restaurant, and analyzed by using the accredited Vidas SLM Salmonella method [13]. Two Finnish patient isolates were sent to Public Health England for comparison by multiple locus variable number of tandem repeats analysis (MLVA) [14] and by PFGE [15].

\section{Epidemiological and traceback investigations}

Trawling interviews were conducted on five cases with laboratory-confirmed $S$. enteritidis genotype 117 (SENT 117) infection notified to the Finnish Infectious Disease Registry (FIDR). An outbreak enquiry was conducted on 22 October 2012 via the Food and Waterborne Diseases Network of the European Centre for Disease Prevention and Control in order to chart the incidence of SE PT1 1B genotype 117 in other European countries. An outbreak caused by SE PT 1B had occurred in an Estonian fast-food restaurant in August to September 2012. By the Finnish infectious disease law, the authorities may gather information on the patients, illness, and exposures in outbreak investigation without additional ethical approvals [16]. The Finnish case-control questionnaire was designed focusing on consumption of suspected food items, based on the trawling interviews that were common to the suspected source in the Estonian investigation (consumption/purchase of chicken or lettuce, unheated spices). Exposure to these items a week before the onset of symptoms was enquired. The Finnish Food Safety Authority conducted a traceback investigation of the ingredients of the suspected food items.

A case was defined as a person with a nalidixic acidresistant SENT 117 or SE PT 1B infection, with symptom onset between 7 August and 4 October 2012 and without history of overseas travel in the week prior to onset. The questionnaire was sent to 53 cases and to 530 age, sex, and municipality of residence-matched controls obtained from the National Population Registry (NPR). Questionnaires were also sent to all $(n=54)$ domestic salmonellosis cases with other than $S$. enteritidis infection identified between 4 August and 8 October 2012 from the FIDR. The data were collected by mail and by an online electronic response form in November 2012. Costs for control selection, posting of questionnaires, and data transfer were obtained from THL. 
Statistical analysis was conducted using $\mathrm{R}$ version 3.0.1 and Stata version 14 [17, 18]. In the case-case study, univariate odds ratios (ORs) were calculated for each exposure. Exact 95\% confidence intervals (95\% CIs) and $P$-values were determined using Fisher's exact test. The sex and age distribution of the cases and control cases were compared by performing Pearson $\chi^{2}$ test of independence on sex and a two-sample non-parametric equality of medians test on age. The data from the matched case-control study were analyzed using univariate conditional logistic regression models: matched ORs, exact 95\% CIs and $P$-values were calculated.

\section{RESULTS}

\section{Description of the outbreak}

Between 7 August and 4 October 2012, 22 SE PT 1B and 31 SENT 117 cases were identified (Fig. 1). Of these, $32(60 \%)$ had not been travelling abroad in the week before the onset of symptoms, $12(23 \%)$ had travelled to Estonia, one to Sweden, and one to Russia. The travel history of seven cases was not known. The cases ranged in age from 13 to 74 years, median age was 27 years, and $28(53 \%)$ were female. Geographically, the cases covered the whole country with the exception of Northern Finland.

The enquiry on 26 October via the Food and Waterborne Diseases Network revealed no increase in the incidence of SENT 117 in the five European countries (Austria, Germany, Ireland, Sweden, and the UK) that responded. In Estonia, an outbreak of SE PT 1B had occurred in August to September 2012.

\section{Hypothesis generation and traceback investigation}

None of the trawling interviewed cases had been travelling abroad prior to the onset of their illness. One of them was a mother to an employee working at a Finnish salad company and who suspected the company's chicken salad was the source of her illness. In August, the company had received a customer complaint from a person that suspected chicken salad as the source of his illness.

In August to September 2012, an outbreak caused by SE PT 1B occurred in an Estonian fast-food restaurant. Twenty-five persons were confirmed to have $S$. enteritidis infection. The suspected source was chicken wrap, from which SE PT 1B had been isolated. The common food items in the Estonian chicken wrap and in the Finnish chicken salad were chicken cubes and iceberg salad. However, the iceberg salad used in Finnish chicken salad was imported from Germany, whereas salad used in chicken wrap in Estonia was of domestic origin. Traceback investigation revealed that the frozen pre-cooked chicken cubes used in both ready-to-eat salad made by a Finnish company and the chicken wrap served in the Estonian restaurant were identical, and originated from the production plant in China. In November 2012 and January 2013, Great Britain made two Rapid Alert Systems for Food and Feed notifications on chicken cubes imported to the UK from the same Chinese production plant as the chicken cubes imported to Finland and Estonia.

The Finnish company had made in total about 4000 portions of various chicken salads and modified atmosphere packages containing chicken cubes, and distributed these to nationwide retailer. Although the company had received a complaint due to suspected Salmonella in their chicken salad, and despite suspicions being voiced by the staff that the chicken cubes were partially raw, the cubes were not tested because the company trusted the Chinese certificate declaring the product Salmonella free. However, the entire staff of the company were tested after the customer complaint, and two asymptomatic carriers of SENT 117 were found.

The local environmental health officials inspected the shops and restaurants where the cases had purchased and consumed the ready-to-eat chicken salad and gathered information about the origin of the chicken used in the salads. They also inspected one warehouse and found the chicken cubes raw. The traceback revealed that six out of eight cases who had eaten chicken salad had bought it from retail shops and two from a restaurant. The chicken had been imported to Finland from the production plant in China.

\section{Microbiological analysis of the foods and comparison of microbiological findings in patients and in food}

At the time of investigation, no frozen pre-cooked chicken cubes were available for testing at the Finnish salad company. Chicken cubes originating from the Chinese production plant were sampled from one Finnish restaurant and one Finnish warehouse, and analyzed for Salmonella with negative results. Four patient isolates and one chicken isolate from the Estonian outbreak as well as samples from 


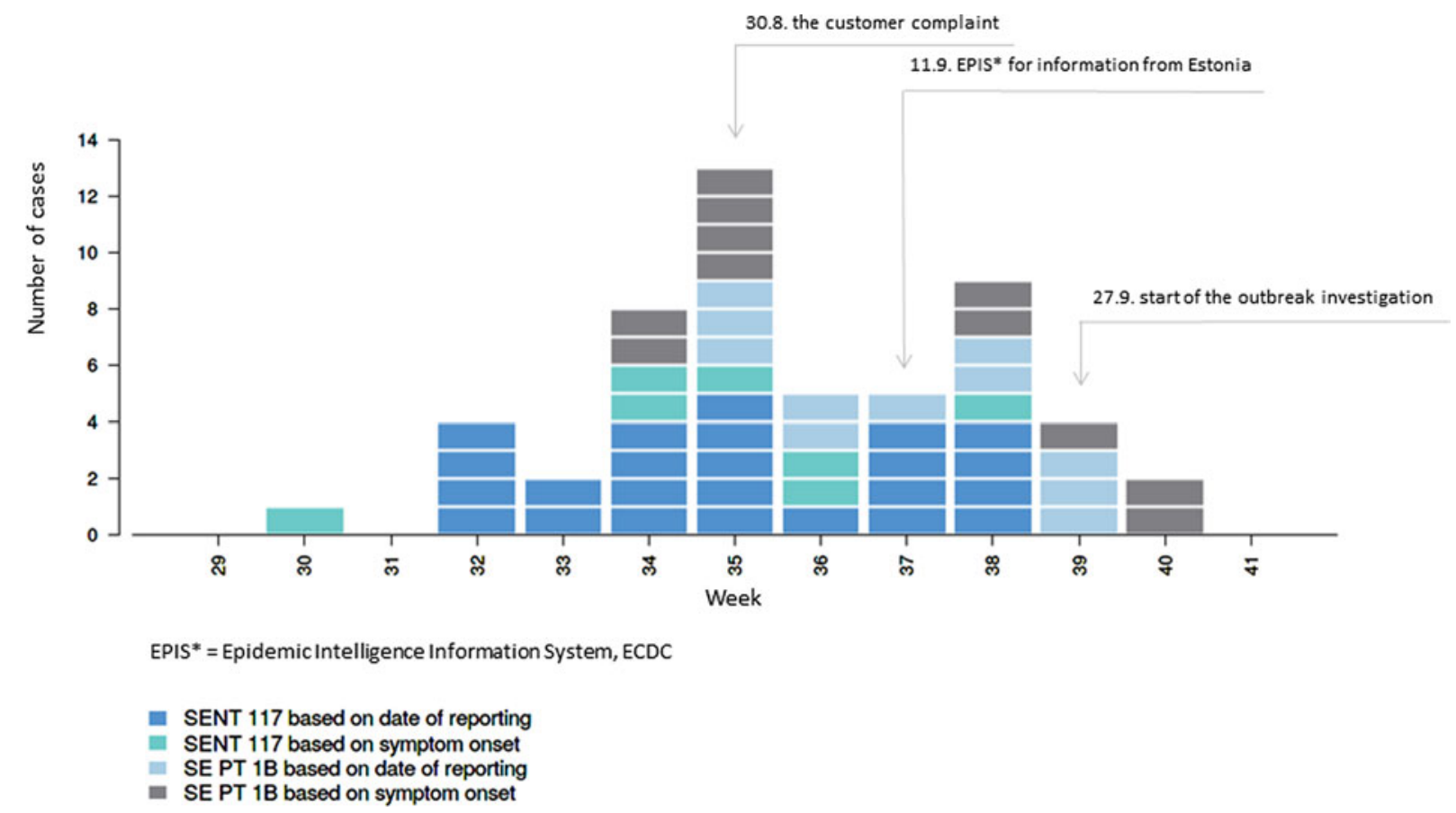

Fig. 1. Number of Salmonella cases according to the onset of symptoms or the date of reporting in the outbreak of Salmonella enteritidis phage type 1B.

chicken cubes tested in the UK shared the same microbiological characteristics as the Finnish patient isolates (PT 1B, genotype SENT 117, and resistance to nalidixic acid, MLVA profile 3-11-9-4-4-4-1-8-8).

\section{Analytical study}

Twenty-two of $53(42 \%)$ cases answered the questionnaire. In order to focus on exposures in Finland, three cases were excluded due to travelling abroad within 1 week before the onset of symptoms. These three cases had travelled to Estonia, and one case had eaten chicken burrito in an Estonian restaurant in August. The median age of the 19 cases was 45 years (range 15-65 years) and $12(63 \%)$ were female. Diarrhea was the predominant symptom $(18 / 19 ; 95 \%)$, followed by mucous stool $(13 / 16 ; 81 \%)$ and fever $(14 / 18 ; 78 \%)$. Seven $(37 \%)$ cases were hospitalized.

For the case-case study, 31 of the $54(57 \%)$ control cases responded to the questionnaire. In the case-case study, one control case was excluded due to a family member that had fallen ill with laboratory-confirmed salmonellosis within 1 week before the onset of the control case's symptom onset. Thus, 19 cases and 30 control cases were included in the case-case study. The median age of the control cases was 31 years (range 1-71 years) and $21(70 \%)$ were male.
A total of 116 of the $530(22 \%)$ age, sex, and municipality of residence-matched controls returned the questionnaire. In the case-control study, 74 controls were excluded: 59 due to non-responding cases, 10 due to diarrhea or laboratory-confirmed salmonellosis in a family member, and five due to travelling abroad. Two cases were excluded due to the non-responding controls. In the case-control analysis, 17 cases and 42 controls were included.

In the univariate analysis of case-case and case-control studies, consumption of chicken salad served outside the home (OR 16 and 6.5 for the case-case and case-control studies, respectively) and the purchase of ready-to-eat chicken salad (OR 18 for case-case and 7.8 for case-control study, respectively) were significantly associated with the illness among the queried food items. Multivariate analysis of the matched case-control data was not performed due to the collinearity problems of the data. In case-case study, also consumption of other salad bulk sales and purchase of ready-made-salad portion (excluding chicken salad) were statistically significantly associated with the illness (OR 11 and 4.5, respectively) (Table 1). Of the cases, $56 \%$ had consumed chicken salad portion.

The sex distribution was statistically significantly different between cases and control cases (Pearson $\chi^{2}$ $P$-value 0.022$)$; control cases were more often male 
Table 1. Exposures associated with the infection: results of univariate logistic regression analysis of case-control and case-case studies, Salmonella enteritidis phage type 1 B outbreak, Finland, August to October 2012

\begin{tabular}{|c|c|c|c|c|c|c|c|c|}
\hline \multirow[b]{2}{*}{ Exposure } & \multicolumn{4}{|c|}{ Matched case-control study } & \multicolumn{4}{|l|}{ Case-case study } \\
\hline & $\begin{array}{l}\text { Cases } \\
\text { exposed/total (\%) }\end{array}$ & $\begin{array}{l}\text { Controls } \\
\text { exposed/total (\%) }\end{array}$ & $\begin{array}{l}\text { Matched } \\
\text { OR }(95 \% \mathrm{CI})\end{array}$ & $P$-value & $\begin{array}{l}\text { Cases } \\
\text { exposed/total (\%) }\end{array}$ & $\begin{array}{l}\text { Control cases } \\
\text { exposed/total (\%) }\end{array}$ & $\begin{array}{l}\text { OR } \\
(95 \% \mathrm{CI})\end{array}$ & $P$-value \\
\hline \multicolumn{9}{|c|}{ Consumption of chicken meals outside home } \\
\hline Chicken salad & $6 / 15(40)$ & $4 / 38(11)$ & $6 \cdot 5(1 \cdot 3-33)$ & $0 \cdot 02$ & $7 / 17(41)$ & $1 / 24(4)$ & $16(1 \cdot 7-149)$ & $0 \cdot 01$ \\
\hline Chicken wrap & $1 / 14(7)$ & $3 / 37(8)$ & $0 \cdot 001<(0-$ Inf $)$ & $0 \cdot 99$ & $1 / 16(6)$ & $2 / 22(9)$ & $0 \cdot 7(0 \cdot 1-8 \cdot 1)$ & $0 \cdot 75$ \\
\hline Chicken hamburger & $0 / 14(0)$ & $3 / 37(8)$ & $0(0-$ Inf $)$ & 0.99 & $0 / 16(0)$ & $2 / 20(10)$ & $0(0-$ Inf $)$ & $0 \cdot 99$ \\
\hline Chicken in pizza & $0 / 11(0)$ & $2 / 38(5)$ & NA & & $1 / 13(8)$ & $1 / 23(4)$ & $1 \cdot 8(0 \cdot 1-32)$ & $0 \cdot 67$ \\
\hline Chicken soup & $1 / 13(8)$ & $3 / 36(8)$ & $0 \cdot 6(0 \cdot 1-6 \cdot 0)$ & $0 \cdot 66$ & $1 / 15(7)$ & $2 / 24(8)$ & $0 \cdot 8(0 \cdot 1-9 \cdot 5)$ & $0 \cdot 85$ \\
\hline Other chicken dish & $5 / 13(38)$ & $11 / 36(31)$ & $1 \cdot 8(0 \cdot 4-7 \cdot 9)$ & $0 \cdot 43$ & $6 / 14(43)$ & $3 / 18(17)$ & $3 \cdot 7(0 \cdot 7-19 \cdot 1)$ & $0 \cdot 11$ \\
\hline \multicolumn{9}{|c|}{ Consumption of chicken or lettuce at home } \\
\hline Frozen pre-cooked chicken cubes & $3 / 16(19)$ & $5 / 41(12)$ & $1 \cdot 7(0 \cdot 3-9 \cdot 3)$ & $0 \cdot 53$ & $4 / 18(22)$ & $2 / 26(8)$ & $3 \cdot 4(0 \cdot 6-21)$ & $0 \cdot 18$ \\
\hline Iceberg lettuce & $4 / 17(24)$ & $18 / 42(35)$ & $0 \cdot 3(0 \cdot 1-1 \cdot 3)$ & $0 \cdot 10$ & $5 / 19(26)$ & $8 / 27(30)$ & $0 \cdot 8(0 \cdot 2-3 \cdot 2)$ & $0 \cdot 80$ \\
\hline \multicolumn{9}{|l|}{ Consumption of ready-made salads } \\
\hline Chicken salad bulk sales & $0 / 17(0)$ & $0 / 42(0)$ & NA & & $1 / 19(5)$ & $0 / 28(0)$ & $>1000(0-$ Inf $)$ & $0 \cdot 99$ \\
\hline Chicken salad portion & $8 / 16(50)$ & $2 / 42(5)$ & $>1000(0-$ Inf $)$ & $0 \cdot 99$ & $10 / 18(56)$ & $0 / 28(0)$ & $>1000(0-$ Inf $)$ & $0 \cdot 99$ \\
\hline Other salad bulk sales & $4 / 16(25)$ & $3 / 39(8)$ & $5 \cdot 3(0 \cdot 9-30)$ & $0 \cdot 06$ & $5 / 18(28)$ & $1 / 29(3)$ & $11(1 \cdot 1-102)$ & $0 \cdot 04$ \\
\hline \multicolumn{9}{|l|}{ Purchase of ready-made salads } \\
\hline Chicken salad portion & $12 / 17(71)$ & $11 / 40(28)$ & $7 \cdot 8(1 \cdot 6-38)$ & $0 \cdot 01$ & $14 / 19(74)$ & $4 / 29(14)$ & $18(4 \cdot 0-76)$ & $<0 \cdot 01$ \\
\hline Other salad portion & $9 / 17(53)$ & $24 / 40(60)$ & $0 \cdot 8(0 \cdot 2-3 \cdot 5)$ & $0 \cdot 79$ & $11 / 19(58)$ & $7 / 30(23)$ & $4 \cdot 5(1 \cdot 3-16)$ & $0 \cdot 02$ \\
\hline Chicken salad bulk sales & $4 / 17(24)$ & $7 / 40(18)$ & $1 \cdot 2(0 \cdot 3-5 \cdot 4)$ & $0 \cdot 85$ & $5 / 19(26)$ & $5 / 29(17)$ & $1 \cdot 7(0 \cdot 4-7 \cdot 0)$ & $0 \cdot 45$ \\
\hline
\end{tabular}


than the cases. The median age did not differ statistically significantly between the groups (Pearson $\chi^{2}$ $P$-value 0.484).

The cost of control selection, posting, and recording the questionnaire data was approximately EUR 2000. The cost for mailing the questionnaires (637 copies) was EUR 1100 and for recording the questionnaire data (12 h at EUR 20/h) EUR 240. In total, 18/22 cases, 26/31 case-controls, and 105/116 controls responded to the questionnaire by mail. The cost for control selection from the NPR was EUR 600.

\section{DISCUSSION}

Over 50 persons throughout Finland fell ill during the outbreak caused by SE PT 1B and associated with exposure to frozen pre-cooked chicken cubes in August to October 2012. In the case-case study, the odds of developing illness were 16 times higher among those who ate chicken salad compared with those who did not. The results of the traceback and laboratory investigations as well as the case-control study supported the results of the case-case study. A large number of chicken salads from a Finnish company had been distributed nationwide. The company used frozen pre-cooked chicken cubes that originated from the same production plant as the chicken cubes identified as a source in an SE PT 1B - outbreak that occurred at the same time in Estonia. Furthermore, in November 2012 and January 2013, the UK reported a finding of $S$. enteritidis in chicken originating from the same production plant. The patient isolates in Estonia and in Finland were indistinguishable from the strains isolated in chicken cubes in Estonia and the UK. This outbreak was investigated in a collaboration between three EU countries (Finland, Estonia, and the UK) and the detection of this multi-country outbreak, and early exchange of information between the public health authorities was assisted by the Epidemic Intelligence Information System hosted at the European Centre for Disease Prevention and Control [19].

The chicken cubes used in the ready-to-eat salad in Finland and in the chicken wrap in Estonia were traced back to the same Chinese production plant. In China, Salmonella contamination is common in raw poultry and $S$. enteritidis is the most frequent finding in chicken carcasses [20]. At the EU level, the most important source of human salmonellosis, and especially $S$. enteritidis infection, is estimated by source attribution to be laying hens, while broiler is a less significant source of
Salmonella [21]. In Finland, Salmonella is very rarely found in broiler breeding flocks. In 1996, Salmonella Infantis contamination was detected at one broilerbreeding holding, and in 2002 at two parent-rearing holdings. Salmonella tennessee was isolated from a sample of day-old chicks at one parent rearing in 2004, and several serotypes at one rearing holding for broiler parents were found in 1999. Since 2004, there have been no positive findings from poultry meat or carcass samples in Finland [3]. Based on the low Salmonella prevalence in domestic livestock production in Finland, the Finnish Salmonella Control Program was established and accepted by the EU in 1995. The program forms the basis for the additional guarantees for importing eggs and meat, granted to Finland by the European Commission. The importance of the program is based on Salmonella control measures, such as feed control, which has been used for decades in Finland. Notably the program for broiler production has been considered economically feasible from the producer's, consumers', and tax payers' points of view [22].

This investigation revealed that the affected Finnish salad company had received a complaint due to a suspicion of Salmonella in their chicken salad. In addition, the staff had suspected that the chicken cubes used were raw. Despite these suspicions, the cubes were not tested or discarded, because the company trusted the certificate given by the production plant that declared the product to be Salmonella free. Since Salmonella can be unevenly distributed in batches, it is possible that low levels or sporadic contamination is not detected in routine sampling of lots. In this investigation, no chicken cubes were available for testing at the Finnish salad company at the time of inspection, and no Salmonella was found in chicken cubes traced back to one restaurant and warehouse, and tested due to the outbreak investigation in Finland.

When Salmonella contamination or an outbreak is suspected, the food business operator is obligated to inform the local environmental health authorities and stop using suspected products. Remaining items from the suspected lot should be kept in storage for official sampling. If applicable, the company should make a product recall. When using cooked, frozen meat in ready-to-eat products, food business operators should visually inspect each lot to confirm that the meat is properly cooked. If raw batches are found, these should either be used for heated products or discarded. Despite certificates for tested Salmonella, food items should be analyzed when Salmonella contamination is suspected in outbreak investigations. 
In 2012, to control for infected staff members as the source of contamination, infectious disease legislation states that an asymptomatic employee that works on foodstuffs premises handling unpacked, easily perishable foodstuffs shall give the employer a report on a laboratory examination or other examination after returning from a country in which he or she may have caught a Salmonella infection [23]. According to the Finnish Food Authority's guidelines, when foodstuff is suspected as the cause of a health hazard, the municipal food control authorities should encourage the employees at foodstuff premises to give laboratory samples for the microbial analyses of pathogens [24]. After the customer complaint, the Finnish salad company tested the whole staff to rule out the possibility of a staff member as the source of contamination and found two staff members with asymptomatic SENT 117 infection. The company implemented as part of their own check plan regular Salmonella tests from staff.

Since 2010, the budget of the Infectious Disease Control Unit in the THL has decreased on a yearly basis. In order to find ways to save resources, we compared two study designs, case-control and case-case approaches, and counted the costs for control selection, posting questionnaires, and recording their data during this investigation. In analytical studies, the most difficult part is often the selection of appropriate controls [25]. A control should be someone that would have had the same possibility to be exposed and infected as the case subject. In a case-control study, the distribution of exposures among cases and a group of healthy persons are compared with each other [25], while in case-case studies, the distribution of exposures is compared between cases and persons with another infection, for example, from the same surveillance database [25]. Although 10 times more controls were contacted to the case-control study than to the case-case study, more controls ended up answering in the case-case study. The case controls replied twice as frequently as the randomly selected controls, while over half of the participating controls were excluded from the study due to non-responding cases or gastrointestinal symptoms. Although the random and automated selection of controls from the population registry minimizes selection bias, the case-case approach controls bias linked to the population of people who tend to visit a doctor when they have gastrointestinal symptoms [25]. The case-case approach selects controls from a subpopulation that is equally prone to visit a doctor and be sampled for
Salmonella. The case-case approach might also minimize recall bias since cases and case controls both have symptoms and response bias might be of lesser concern compared with conventional case-control study, since the serotype is unlikely to influence the decision to participate in interviews [26]. However, the difference in sex distribution between cases and control cases in our study can lead to potential bias in the results of presented case-case analysis. The differences in food consumption habits between sexes should be addressed thoroughly when case-case approach is used in analysis of foodborne outbreaks.

In our study, no difference was seen in the OR results for chicken exposures in case-case and casecontrol studies. Since the electronically implemented case-case study saves time, effort, and money [25, 26], it is useful in Salmonella outbreak investigations when two groups of cases can be determined for comparison from the surveillance data and a sufficient number of case controls can be included. The more cases are included in the study, the easier it is to detect a statistical association between exposure and outcomes. One control per case, however, is often enough in an outbreak of 50 cases or more [27]. In smaller outbreaks, more controls per case can be used, but increasing the number of controls to over four per case is rarely useful.

\section{ACKNOWLEDGEMENTS}

The authors would like to thank all the experts from THL, Evira, municipal authorities and experts in Estonia and the UK who contributed to the outbreak investigation and all the questionnaire respondents for taking part in the study.

\section{AUTHOR CONTRIBUTION}

$\mathrm{SH}$ contributed to the questionnaire design, collection of data, and drafted the manuscript as the lead writer. $\mathrm{AP}$ and HL contributed to the traceback investigation. SS was responsible for the microbiological investigation of the human samples and contributed to the comparison of human and food samples. JS and ID were responsible for the outbreak investigation in Estonia. EDP was responsible for laboratory analysis of food samples and contributed to the comparison of human and food samples. ST contributed to the questionnaire design, collection of data, and performed statistical analysis of data. RR-F was responsible for the epidemiological investigation and contributed to 
the study design, questionnaire design, analysis of the data, and manuscript writing. All co-authors critically reviewed the draft of the paper and approved the final version.

\section{DECLARATION OF INTEREST}

None.

\section{REFERENCES}

1. European Food Safety Authority. The European Union summary report on trends and sources of zoonoses. Zoonotic agents and food-borne outbreaks in 2010 (http://www.efsa.europa.eu/en/efsajournal/doc/2597. pdf). EFSA Journal 2012; 10: 2597.

2. National Institute for Health and Welfare. Infectious Diseases in Finland 2015 (http://urn.fi/URN:ISBN:978952-302-710-7).

3. The Finnish Zoonosis Center. Salmonelloosi (http:// www.zoonoosikeskus.fi/portal/fi/zoonoosit/bakteerien_ aiheuttamat_taudit/salmonella/).

4. Finnish Food Safety Authority Evira. Ruokamyrkytykset Suomessa 2010 (https://www.evira.fi/globalassets/tietoaevirasta/julkaisut/julkaisusarjat/elintarvikkeet/ ruokamyrkytykset-suomessa-2010.pdf).

5. Finnish Food Safety Authority Evira and the National Institute for Health and Welfare. Elintarvike- ja talousvesivälitteiset epidemiat Suomessa 2011-2013 (http://urn.fi/URN:NBN:fi-fe201603248900).

6. National Institute for Health and Welfare. Infectious Diseases in Finland 2014 (http://urn.fi/URN:ISBN:978952-302-481-6).

7. Finnish Food Safety Authority Evira. Microbiological hazards in food (https://www.evira.fi/globalassets/ tietoa-evirasta/julkaisut/julkaisusarjat/elintarvikkeet/ elintarvikkeiden_mikrobiologiset_vaarat.pdf).

8. Guibourdenche M, et al. Supplement 2003-2007 (No. 47) to the White-Kauffmann-Le Minor scheme. Research in Microbiology 2010; 161: 26-29.

9. European Society of Clinical Microbiology and Infectious Diseases. European Committee on Antimicrobial Susceptibility Testing. EUCAST. Version 3.1 (http:// www.eucast.org).

10. Clinical and Laboratory Standards Institute 2010: M100S20U, vol 30, no15 (https://www.researchgate.net/file. PostFileLoader.html?id=50f0395de39d5e8368000022\& assetKey=AS\%3A272179910905873\%401441904155623).

11. Ward LR, de Sa JD, Rowe B. A phage-typing scheme for Salmonella enteritidis. Epidemiology and Infection 1987; 99: 291-294.

12. Centers for Disease Control and prevention. Salmonella. Pathogens \& protocols (http://www.cdc.gov/pulsenet/ pathogens/salmonella.html).
13. Crowley E, et al. Evaluation of VIDAS Salmonella (SLM) easy Salmonella method for the detection of Salmonella in a variety of foods: collaborative study. Journal of AOAC International 2011; 94: 1821-1834.

14. Hopkins KL, et al. Standardisation of multilocus variable-number tandem-repeat analysis (MLVA) for subtyping of Salmonella enterica serovar enteritidis. Eurosurveillance 2011; 16: 32.

15. Peters TM, et al. The Salm-gene project- a European collaboration for DNA fingerprinting for food-related salmonellosis. Eurosurveillance 2003; 8: 46-50.

16. Communicable Diseases Degree, 1227/2016. (http:// www.finlex.fi/fi/laki/alkup/2016/20161227).

17. R Core Team. R: A language and environment for statistical computing. $\mathrm{R}$ Foundation for Statistical Computing (http://www.R-project.org/).

18. StataCorp. Stata Statistical Software: Release 14. College Station, TX: StataCorp LP, 2015. (http:// www.stata.com).

19. Gossner CM, et al. European food and waterborne diseases study group C. Event-based surveillance of foodand waterborne diseases in Europe: urgent inquiries (outbreak alerts) during 2008 to 2013. Eurosurveillance 2015; 20: 19-28.

20. Yang B, et al. Counts, serotypes, and antimicrobial resistance of Salmonella isolates on retail raw poultry in the People's Republic of China. Journal of Food Protection 2014; 77: 894-902.

21. DE Knegt LV, Pires SM, Hald T. Attributing foodborne salmonellosis in humans to animal reservoirs in the European Union using a multi-country stochastic model. Epidemiology and Infection 2015; 143: 1175 1186.

22. Kangas S, et al. Costs of two alternative Salmonella control policies in Finnish broiler production. Acta Veterinaria Scandinavica 2007; 49: 35.

23. Communicable Diseases Act, $1376 / 2006$ (https://www. finlex.fi/fi/laki/kaannokset/1986/en19860786.pdf).

24. Finnish Food Safety Authority Evira. Toiminta elintarvikkeisiin liittyvissä terveysvaaratilanteissa (http:// www.evira.fi/files/attachments/fi/evira/lomakkeet_ja_ ohjeet/elintarvikkeet/terveysvaara/eviran_ohje_1028_1_ fi.pdf).

25. Giesecke J. Modern Infectious Disease Epidemiology, 2nd edn. London: Arnold, 2002.

26. Zenner D, et al. The serotype case-case design: a direct comparison of a novel methodology with a case-control study in a national Salmonella enteritidis PT14b outbreak in England and Wales. Epidemiology and Infection 2013; 141: 2346-2353.

27. World Health Organization. Foodborne Disease Outbreaks: Guidelines for Investigation and Control. Geneva: World Health Organization, 2008 (http:// www.who.int/foodsafety/publications/foodborne_disease/outbreak_guidelines.pdf). 